\title{
La historia de las ideas en América Latina, modelo para desarmar"
}

LeONARDo Tovar GonZÁlez"*

\begin{abstract}
El subtítulo "Modelo para armar" podría llevar a creer que las diferentes partes del texto (...) se componen como piezas permutables. Si algunas lo son, el armado a que se alude es de otra naturaleza, sensible ya en el nivel de la escritura donde desplazamientos y recurrencias buscan liberar de toda fijeza causal, pero sobre todo en el nivel del sentido donde la apertura a una combinatoria es más insistente e imperiosa. La opción del lector, su montaje personal de los elementos del relato, será en cada caso el libro que ha elegido leer. Julio Cortázar (1968)
\end{abstract}

Tomado de la advertencia preliminar de la novela 62 Modelo para armar, el epígrafe nos exime de mayores explicaciones sobre el origen del título de nuestra propuesta, y espero que el sentido "en construcción" se evidencie paulatinamente al hilo de la exposición. Para enunciar a intencionalidad del texto, recurriremos a otra paráfrasis, esta vez de los "Escolios a un texto implícito" del célebre pensador colombiano

* Una versión anterior fue presentada en el "Congreso Internacional de Pensamiento Latinoamericano. Una mirada desde las ciencias sociales y humanas”, celebrado en la Universidad Minuto de Dios, sede Bello, entre el lunes 20 y el miércoles 22 de octubre de 2014.

** Universidad Santo Tomás. Integrante de la "Sociedad Colombiana de Filosofía”. 
Nicolás Gómez Dávila, en tanto concebimos el texto como una especie de protocolo de un seminario virtual entre estudiosos de la "historia de las ideas" en América Latina y otras latitudes.

El entrecomillado es un guiño analítico para indicar que no nos referiremos al factum de la historia de las ideas (por ejemplo, a la reseña sobre la escolástica, o el positivismo, o el marxismo, o cualquier otro momento histórico de las ideas en la región) sino a los problemas metodológicos que surgen del enfoque que se ha dado en denominar "historia de las ideas", representado eminentemente por filósofos latinoamericanos como Arturo Ardao, Leopoldo Zea, Arturo Andrés Roig y más recientemente, Pablo Guadarrama y Horacio Cerutti.

En el protocolo latente que me he propuesto elaborar, resonarán también las voces de mis compañeros del grupo de investigación Estudios en pensamiento filosófico en Colombia y América Latina- Bartolomé de Las Casas, O.P. de la Universidad Santo Tomás ${ }^{1}$, sin que de ello se infiera que todos nosotros compartimos la misma lectura sobre el programa de la "historia de las ideas" (formulada la aclaración en adelante nos ahorraremos las comillas), pues como sabemos Santiago CastroGómez es uno de sus más fervorosos contradictores. Por supuesto, como voz cantante cargo la responsabilidad de cualquier disonancia o desentone en este coro secreto.

A propósito, valga aclarar que esta exploración sobre los límites y alcances de la "historia de las ideas en América Latina" se adelantó dentro del desarrollo de la línea de investigación sobre historia e historiografía de la filosofía en Colombia y América Latina. Y de manera más específica, hizo parte de la indagación sobre el marco conceptual del proyecto "El proceso de la filosofía en Colombia. Hacia la conformación de una memoria filosófica nacional”, investigación que se llevó a cabo entre 2012 y 2014.

Pues bien, de carácter constructivo, pondremos en la primera parte el programa latinoamericano de la historia de las ideas sobre el fondo de la historia de la filosofía, de manera que se patentice el carácter

1 Santiago Castro, Damián Pachón, Ángela Niño, Gloria I. Reyes, César Vásquez, Édgar López, Claudia Giraldo, entre otros. 
eminentemente filosófico de la propuesta abordada. El segundo ítem seguirá un propósito deconstructivo, al revelar las insuficiencias y falencias de la historia de las ideas puesta sobre el fondo de nuevas miradas de la historia social y cultural como la "historia de los conceptos", la "historia de los lenguajes políticos" o la genealogía. Con ánimo reconstructivo, en el apartado final exploraremos más allá de esencialismos o contra-esencialismos (que al cabo son otra forma de esencialismo) la vigencia de la tradición investigativa de la historia latinoamericana de las ideas, así las revisiones consignadas nos motiven a cambiar las etiquetas y el curso mismo de los proyectos emprendidos sobre dicha huella.

\section{Modelo para armar: la historia de las ideas como historia de la filosofía en América Latina}

Para formar parte de la historia de la filosofía, una idea debe poseer una significación filosófica intrínseca, capaz de despertar el interés del hombre contemporáneo y de representar algo discutible y hasta verdadero. Para formar parte de la historia de las ideas solo se requiere que la idea en cuestión tenga influencia histórica en los asuntos humanos (Scruton, 2013, p. 28).

Esta tajante demarcación entre historia de la filosofía e historia de las ideas trazada por Roger Scruton (2013) en su "Breve historia de la filosofía moderna", no es más que una variante actualizada en clave analítica de la oposición que ya había planteado a inicios del siglo XIX Hegel (1985) en sus "Lecciones sobre historia de la filosofía" entre esta y una mera doxografía de las opiniones filosóficas. Tanto en el filósofo alemán como en el autor contemporáneo, el criterio distintivo radica en que la historia de la filosofía se guía por la búsqueda inmanente de la verdad en el decurso de las teorías filosóficas, mientras la doxográfica historia de las ideas se concentra en la influencia histórica de dichas ideas en la sociedad, sin ocuparse de su pretensión de validez.

De esta manera, la historia de la filosofía antes que una clase de historia particular, sería ella misma un modo de hacer filosofía, encargado 
en Hegel de revelar la génesis histórica de la verdad, y en Scruton de rastrear el relativo progreso que cabe obtener en el filosofar. Así puedan coincidir sobre el mismo objeto, una cosa es rastrear los efectos históricos del roussoniano "contrato social" y otra establecer su significación netamente filosófica en la teoría política, y anotemos de paso que este ejemplo aportado por el scholar anglosajón es tanto más elocuente en América Latina, donde nuestras repúblicas independientes se edificaron siguiendo los derroteros del contractualismo moderno.

A la luz de esta división, el seguimiento de esa y otras ideas políticas en la región, nada tendría que ver con la historia filosófica propiamente dicha, reservada para hitos de verdad que de ninguna manera se han producido en el subcontinente.

Paradójicamente, las visiones sobre la filosofía y su historia que cuestionan o por lo menos relativizan este primado epistemológico de la verdad, reconfirman por defecto esa concepción ortodoxa de la historia de la filosofía. Por ejemplo, Isaiah Berlin después de contribuir a la filosofía del lenguaje y a la filosofía política, incursionó en la historia de las ideas con algunas monografías sobre autores que ilustran ciertas tendencias históricas (v. gr. Herder y el pensamiento reaccionario), bajo el convencimiento de que la pretensión de verdad única es una ilusión dogmática que solo anida en los sistemas filosóficos. Y Richard Rorty en su tipología sobre los cuatro modos de historiar la filosofía, enumera la mencionada doxografía, la hegeliana Geistesgeschichte o "historia del espíritu universal”, la continental "reconstrucción histórica” y la analítica "reconstrucción racional”, pero adrede deja fuera de la clasificación su opción por una historia intelectual atenta precisamente a la incidencia pragmática de las ideas en cada contexto histórico, sin importar su pertenencia o no al género filosófico.

En resumen, si la filosofía -su historia incluida- se sigue considerando como búsqueda de la verdad, no cabe confundirla con la historia de las ideas, y si se duda del baremo de la verdad, entonces la historización de las ideas entra a ocupar el lugar de la historia filosófica, que es lo que de hecho ha ocurrido con ciertos acercamientos a la historia del pensamiento filosófico como los adelantados bajo la perspectiva CTS (ciencia, tecnología y sociedad). 
Pues bien, el programa latinoamericano de la historia de las ideas, inspirado por el historicismo circunstancialista de Ortega, diseñado por el historicismo cultural de José Gaos, ejecutado por el historicismo político de Leopoldo Zea y sus discípulos en México y otros países del continente, "textualizado" por la teoría del discurso en Arturo Andrés Roig, "materializado" por los filósofos marxistas, "humanizado" por Pablo Guadarrama y examinado metodológicamente por Horacio Cerutti, nada tiene que ver con ese divorcio entre historia filosófica e historia de las ideas. Al contrario, como ya mostró José Luis Abellán para el caso hispánico en tesis que se puede extender a todo el mundo ibero-americano, la latinoamericana historia de las ideas ha sido postulada no solo como historia de la filosofía en la región, sino como ejercicio filosófico en sí mismo, que en su misma práctica discursiva responde performativamente al interrogante sobre la existencia y posibilidad de la filosofía latinoamericana.

Para comprender esta confluencia entre historia filosófica e historia de las ideas, debemos reparar en la inversión historicista aplicada a Hegel, comparable a la inversión materialista que sobre él operó Marx. Bajo el énfasis de la "reconstrucción racional" con que proceden los filósofos analíticos, la apelación a las doctrinas del pasado es una opción heurística o didáctica, pero lo que verdaderamente importa es la capacidad del filósofo para pensar estructuralmente los problemas que aborda, no la reconstrucción detallada de la historia de dichos problemas.

De ahí que Wittgenstein haya podido legar las enseñanzas más significativas a la filosofía contemporánea sin mencionar casi a los autores de la tradición filosófica. En el hegelianismo, en cambio, el recurso a la historia no es una opción arbitraria sino un fundamento estructurante, dado que la verdad no se da dogmáticamente de una vez y para siempre, sino se configura dialécticamente a través del tiempo, isomórfica aunque no sincrónicamente en la historia universal del espíritu y en la historia interna de los sistemas filosóficos. Que la filosofía es su tiempo aprehendido en conceptos, como señala el conocido dichtum del prólogo a la "Filosofía del derecho", ello en Hegel no significa que cada tiempo posee su propia verdad, sino que la verdad, que por definición es única, se despliega en el tiempo. 
Pues bien, el historicismo procede invirtiendo la historia sub specie veritatis planteada por Hegel, y postula a cambio la verdad sub specie historiae, lo que no significa negar la verdad ni relativizarla, pero sí adoptar una postura perspectivista de la que el circunstancialismo orteguiano es buena muestra.

Por ello, los filósofos latinoamericanos historiadores de las ideas formados directa o indirectamente en dicha escuela, no han pretendido sustituir la historia de la filosofía ni hacer una especie de historia filosófica para pobres, es decir, para pueblos carentes de una genuina tradición filosófica original, en que a falta de pensadores creadores como Comte y Spencer debemos contentarnos con hablar de sus epígonos regionales como Gabino Barreda o Rafael Núñez.

En realidad, la historia de las ideas entendida como recepción de los sistemas filosóficos europeos, a menudo denigrada como puro consecuencialismo, se ilumina con una luz nueva, en tanto se entienda que la repercusión histórica de las doctrinas (en los ejemplos aducidos respectivamente en el sistema educativo mexicano y en el sistema político colombiano), hace parte de la historia misma de la verdad de las propuestas filosóficas, de manera que el análisis de la validez del positivismo no se agota en el estudio de las tesis de sus fundadores y la confrontación con doctrinas rivales como la escolástica o el vitalismo, sino incluye la consideración sobre sus efectos históricos pero también propiamente filosóficos en su contexto europeo de nacimiento así como en otras latitudes por ejemplo, los países latinoamericanos.

Si dicho seguimiento se hace por medio de un rastreo extrínseco de influencias meramente literarias, o se emprende una arqueo-genealogía de las prácticas discursivas y culturales en que efectivamente se encarnan dichas tendencias ideológicas, me parece que ya es una cuestión del método adoptado, importante en sí misma, pero que en nada afecta la intencionalidad profunda del programa investigativo de la latinoamericana historia de las ideas.

Jugando con la imagen, podríamos decir entonces que si la inversión marxiana del idealismo hegeliano puso otra vez al mundo sobre sus pies, la inversión historicista lo puso de nuevo al derecho, revelando que la producción filosófica de la verdad es inseparable de su producción histórica. La historia de las ideas filosóficas en América Latina pero 
también ella en general nos ha enseñado no solo que son inseparables historia de la filosofía e historia de las ideas, sino que esta última precede a aquella, en tanto la cuestión intra-filosófica de la verdad solo se reconoce en los efectos históricos de verdad de cada doctrina, como también la hermenéutica gadameriana nos ha revelado.

Para tomar otro ejemplo de Scruton (2013) que en su propia formulación es ya una autorefutación, que el historiador de la filosofía moral deba detenerse en la ética de Kant sin reparar en la Libertad del cristiano de Lutero que le sirve de fuente histórica (varío ligeramente el referente), al cabo implicará que será un mal historiador y peor filósofo moral, pues sin el horizonte de la reforma resulta del todo imposible comprender la verdad de la moral kantiana. Y prospectivamente, el valor de verdad de la filosofía de Marx solo se puede determinar al hilo de la historia filosófica pero también política de los marxismos, por supuesto sin que culpemos al pensador alemán de todas las faltas cometidas en su nombre.

Ahora bien, de esta latinoamericana historia de las ideas comprendida como historia de la filosofía en América Latina, resultan tres consecuencias que si bien se han señalado críticamente en diagnósticos como la Crítica de la razón latinoamericana de Santiago CastroGómez o los cuestionamientos de Elías Palti desde la historia intelectual, en el marco de nuestra recontextualización conceptual resultan por lo menos plausibles.

La creencia en que la verdad se configura a través del tiempo, en efecto implica adoptar una teleología histórica, que si bien no tiene el carácter del indefectible telos especulativo del hegeliano espíritu universal, sí implica ubicar las ideas filosóficas dentro del proyecto de una finalidad histórica, sea esta la identidad cultural, el humanismo ético, o la liberación política. Unida a la teleología histórica, la búsqueda de la verdad filosófica e histórica comporta también confianza en el sentido, tanto en el marco de la realización personal, como en la esfera de la organización de la sociedad y en general del proyecto histórico de los pueblos del continente.

Desde luego, en cada momento la utopía invocada se hará a imagen de los grupos representados en estas búsquedas ideológicas, y de allí que "la ciudad letrada" blanca o mestiza, burguesa y masculina haya prevalecido en la mayoría de interpretaciones, pero nada impide que 
los cambios educativos y socioeconómicos propicien la construcción de sentidos alternativos en términos de grupos étnicos, clase social o género, como de hecho ya ha sucedido. Reparemos por ejemplo en el tránsito del arielismo de Rodó al calibanismo de Fernández Retamar, y tentativamente podríamos sugerir en clave de género a Miranda (mujer y víctima silenciada) como nuevo símbolo latinoamericano en el siglo XXI.

La última consecuencia de la historia de las ideas filosofante, por usar de nuevo un giro hegeliano, reside en que ella no aparece como una exploración, o una preparación, ni siquiera un auxiliar de la anhelada historia de la filosofía latinoamericana, sino se constituye ella misma en el autocumplimiento de dicha filosofía.

Como veremos en el segundo apartado, no sin motivo los críticos han denunciado la sobrerrepresentación de los historiadores de las ideas y la sobredeterminación de la historia de las ideas, pero cabe señalar que la concepción de la historia de las ideas filosóficas bajo el signo de la verdad, implica que esta se entienda como un ejercicio filosófico, que en su misma indagación sobre la presencia histórica de las ideas filosóficas y su papel en la teleología del continente, construye performativamente el sentido que aspira a encontrar. Se nos dirá que este es un procedimiento de autovalidación que se inmuniza contra la crítica, pero creo que precisamente ese es el carácter de todo discurso filosófico, que en su postulación de las condiciones de racionalidad de lo real, crea las condiciones para su propia inteligibilidad como realidad.

Al cabo, descubrimos que la historia de las ideas sin comillas no puede ser otra que la entrecomillada "historia de las ideas", pues es a la luz de la mirada crítica de los historiadores de las ideas, que los acontecimientos de la historia ideológica han adquirido una significación filosófica. 


\section{Modelo para armar y desarmar: la historia de las ideas como filosofía de la historia en América Latina}

En el apartado anterior, hemos intentado ofrecer una visión "caritativa" del proyecto latinoamericano de la "historia de las ideas", si por tal mirada se entiende establecer el marco conceptual en el que dicho proyecto adquirió su sentido. Sintéticamente, se trataba de indagar en la función de las ideas en el pasado de la región, con el fin de fundir en una sola búsqueda la construcción de la verdad filosófica y el descubrimiento de la identidad cultural del subcontinente y de los países que lo conforman. Pero donde reside su fuerza, surgen también sus debilidades, pues pronto se revela que las filosofías nacionales y la pretendida filosofía continental articuladas sobre la historia de las ideas, así como su mensaje político identitario, en realidad fueron (han sido) funcionales a la ideología del Estado nación, sea en versión liberal-burguesa, populista-autoritaria o incluso marxista-cesarista.

No obstante, antes que profundizar en los impases ideológicos de esta historiografía filosófica latinoamericana, queremos examinar las limitaciones metodológicas que están en la base de las dificultades prácticas. Con tal objeto, pasaremos revista a algunas transformaciones recientes en el paradigma de los estudios históricos y su repercusión en la historia de la filosofía, en particular de la filosofía política.

He dicho recientes, pero en realidad se remontan a varias décadas atrás, así nuestros filósofos historiadores y en gran medida tampoco nuestros historiadores filósofos se hayan percatado de dichos cambios. Si la acostumbrada historia de las ideas puede ser caracterizada en definitiva como un cruce entre la inversión historicista y la inversión marxista del hegelianismo, en la nueva historiografía política, con ecos en los demás campos, estamos frente a la simbiosis entre el giro lingüístico y el giro pragmático.

Según Elías Palti (2016), uno de los historiadores latinoamericanos que más se ha dejado permear por esta tendencia, al menos dos matrices nutren la nueva visión, a saber, el análisis retórico auspiciado por la llamada escuela de Cambridge con Quentin Skinner y J. G. A. 
Pocock a la cabeza, y el modelo de la "Begriffsgeschichte" ("historia de los conceptos") auspiciado por R. Koselleck. Por economía de tiempo, vamos a concentrarnos en la primera de estas vertientes, sin que desde luego, su posición agote las modificaciones historiográficas adoptadas.

En "Meaning and understanding in the history of ideas", artículo que data de 1969 compilado en el primer volumen de sus Visions of politics Skinner (2007), cuestiona la noción canónica de la historia de las ideas como explicitación de los conceptos perennes contenidos en la literatura moral, política o religiosa del pasado. Contra dicha concepción sub specie eternitatis, Skinner recurre a la noción de paradigma utilizada en la historia del arte y de la ciencia, con el fin de mostrar que las ideas obtienen su significación específica de los usos y comprensiones propios de cada período y situación históricos, de donde intentar una lectura longitudinal indiferenciada de conceptos como democracia, república, Estado, implica incurrir en un flagrante anacronismo.

Para nuestro analista, la falacia de fondo reside en "la asimetría entre el significado que el observador estima justificable dentro de un episodio histórico dado y el sentido de tal episodio en sí mismo" (p. 73). No niega Skinner que se puede detectar una gran continuidad en la filosofía moral y política occidental que se refleja en la estabilidad de varios conceptos y modos de argumentación, pero el problema estriba en suponer que "existe algo así como un arsenal de cuestiones alrededor del cual giran todos los pensadores” (Skinner, 2007, p. 86), desconociendo que "la única historia de las ideas que puede escribirse es la de los usos argumentativos de tales ideas” (Skinner, 2007, p. 86).

La alternativa metodológica consiste en adoptar la comprensión de textos como modelo interpretativo "esencialmente lingüístico" que permite ubicar el contexto social del texto dentro del mismo texto. Para Skinner (2007) el valor filosófico de la historia de las ideas no reside en reseñar los problemas perennes presentes en los textos clásicos del pasado, sino en descubrir "las respuestas individuales dadas a cuestiones individuales" (p. 88).

Por similares senderos, Pocock en Politics, language and time: Essays on political thought and history (1989) parte de constatar las dificultades tradicionales (in illo tempore) en distinguir "filosofía política", "teoría política”, "historia de la filosofía política”, "historia del pensamiento 
político" y otras expresiones cercanas, en tanto no queda claro cómo en cada una de ellas se acota el objeto "político" que les es común.

El criterio de la mayor abstracción formal que sería el propio de la filosofía, no resulta satisfactorio, pues en todos los casos el estudioso se halla frente a abstracciones, y además lo que hoy tomamos como muestra de una sofisticada reflexión filosófica, en su tiempo pudo hacer parte de acalorados debates políticos (piénsese por ejemplo en el Tratado teológico-político de Spinoza, el ejemplo es mío).

Ante este enredado panorama, nuestro filósofo de la historia política se inspira en la nueva historia de la ciencia de Thomas Kuhn, con el fin de proponer como paradigma emergente que los estudios concernientes a este campo se concentren en los lenguajes de la política, derivando de allí los diversos usos (filosófico, histórico, directamente político) que se ejecuten con dicho lenguaje, "Conocer un lenguaje es conocer las cosas que pueden ser hechas con él ...” (p. 28) -traducción mía-, anota Pocock (1989) apropiándose del austiniano "to do things with words”, y agrega que un estudioso debe ser consciente de la diversidad de lenguajes y de contextos que se han ocupado de lo político. Sea en su sentido clásico o moderno, la filosofía es apenas una de las actividades intelectuales especializadas en que se ha articulado la política, junto con la historia, la ciencia política, etc., sin que tengamos que considerar una auxiliar de otra de ellas.

Desde el enfoque retórico-pragmático de los lenguajes políticos, las distinciones entre competencias serán más bien de grado, de manera que "si al filósofo político le concierne asegurar el estatuto de los diferentes órdenes (de discurso) para distinguirlos unos de otros, el historiador comprueba si esos órdenes fueron o no distintos en efecto, y da cuenta de lo que de hecho sucedió como resultado de aquellos..." (Pocock, 1989, p. 21).

A esta altura, conviene reflexionar en que si frente a la "historia de la filosofía" tradicional, la historia de las ideas latinoamericana pecaba por exceso de historia, frente a esta historiografía transformada, peca por déficit histórico.

Como lo ha mostrado Palti, quien ha escudriñado sistemáticamente las insuficiencias y deficiencias de la historia de las ideas como modelo para historiar el pensamiento político en la región (ver "De la 
"historia de las ideas" a la historia de los lenguajes políticos", entre otros muchos), filósofos historiadores como Leopoldo Zea han partido de casilleros conceptuales preconcebidos sobre el pensamiento político occidental (escolástica, ilustración, positivismo, marxismo, neoliberalismo, etc.) y han "encasillado" (valga la redundancia) a la fuerza las diversas expresiones políticas de la región, según un modelo también preconcebido de teleología histórica (la nación, la liberación, la democracia) que ignora olímpicamente los efectivos usos de los lenguajes políticos en cada momento.

Si de la historia de las ideas políticas deductivista y reduccionista pasamos al estudio pragmático de los discursos políticos efectivos en la prensa, los tribunales, la literatura, los manuales escolares, los sermones religiosos, etc., nos damos cuenta por ejemplo de que los pensadores políticos del pasado (v.gr. Luis María Mora, Domingo Faustino Sarmiento, José Martí, Rafael Núñez) no representaron de manera inconmovible el segmento del espectro político en que hoy lo ubica el historiador de las ideas, sino se expresaron y actuaron políticamente según los intereses y tendencias en juego en cada caso.

Sin ponernos ahora de defensores de oficio de la obra del maestro Zea y otros de los impugnados historiadores de las ideas, debemos señalar que la diversidad de fuentes, la evolución de los pensadores, la multiplicidad de roles, no es algo ajeno a la historiografía política latinoamericana, si bien es lógico que en estudios de gran espectro se enuncien generalizaciones cuestionables cuando se entra al detalle. Pero más allá de estas precisiones, resulta claro que el proyecto mismo de una teleología filosófica montada sobre la historia política no resulta satisfactorio desde el punto de vista de la historia de los lenguajes políticos, como tampoco es aprobada desde perspectivas filosóficas que cuestionan los presupuestos epistemológicos y ontológicos normativos de aquella propuesta.

Brevemente, nos referiremos a las críticas esgrimidas por Javier Sasso en La filosofía latinoamericana y la construcción de su historia y por Santiago Castro-Gómez en Crítica de la razón latinoamericana, ambas obras de 1998. Concentrada más en los aspectos metodológicos la primera y más en el alcance mismo del proyecto la segunda, los dos autores coinciden en que la habitual historia de las ideas ha operado 
por medio de un metarrelato en el que se fuerza a los autores y discursos del pasado a seguir un libreto determinado a priori por el historiador, sin atender a las efectivas prácticas discursivas en que sus mensajes fueron proclamados.

Bajo entelequias como la "filosofía americana", la "identidad nacional", la "liberación política", se elude la investigación concreta del sentido histórico de los mensajes comunicados en cada contexto histórico. Retiradas las anteojeras teleológicas, descubrimos que ni Alberdi fundó la "filosofía americana" ni la discusión entre positivistas y antipositivistas definió la identidad latinoamericana, ni la "filosofía de la liberación" ha orientado los movimientos revolucionarios.

Como alternativas metodológicas, el filósofo uruguayo sugiere la teoría crítica del discurso (tanto en versión semiótica como en la pragmática de Austin) y la arqueología de Foucault, salidas que equipara en tanto ambas se concentran a su modo, en los actos discursivos y sus efectos históricos. Potenciando este camino, el filósofo colombiano ha propuesto una genealogía de las prácticas filosóficas en el país y el continente, concentrada no en develar los significados ocultos de los filosofemas latinoamericanos o en destacar su papel en la gesta filosófico-política continental, sino de determinar los efectos de verdad y las variaciones de poder de las concepciones filosóficas en las instituciones y hábitos históricos.

Así, por ejemplo, la ilustración no sería tanto la fuente de inspiración ideológica de los procesos independentistas de las naciones del continente latinoamericano en las primeras décadas del siglo XIX, sino cubriría el conjunto de "dispositivos de modernización" que reestructuraron el ejercicio del poder en el imperio español desde las reformas borbónicas. Y para dar otro ejemplo, la normalización filosófica de la primera mitad del siglo XX, antes que obedecer al propósito de profesionalización filosófica autónoma trazado por Francisco Romero, se ubicaría en el programa de construcción de los saberes sociales y humanos afines a la modernización capitalista. Bajo el factum de la globalización, de hecho el programa identitario de la filosofía latinoamericana ha quedado caduco, y por eso corresponde pasar a un pensamiento crítico que revele las múltiples subjetividades de clase, género, etnia e ideología que bullen en el interior del continente, lejos de las miradas 
monolingüísticas sobre la unidad latinoamericana consignadas por la historia de las ideas.

\section{Modelo para armar, desarmar y rearmar: la historia de las ideas como filosofía en América Latina}

Dos acontecimientos en apariencia desconectados, enmarcan el cierre de mi examen sobre la historia de las ideas. A modo de contra-celebración del Bicentenario de la independencia de las naciones latinoamericanas, el periodista Andrés Oppenheimer publicó en 2010 el libro Basta de historias, en que realiza un crudo balance de la calidad de la educación en el subcontinente, atribuyendo las deficiencias a que nuestros pueblos permanecen obsesionados con la revisión del pasado, con su secuela de odios heredados, en lugar de prepararse para las transformaciones científicas y tecnológicas que requiere el globalizado mundo del siglo XXI.

Y dentro del sistema educativo por competencias adoptado hace ya varios años en Colombia, en la evaluación estatal a la cual deben someterse todos los estudiantes que culminan la educación media, a partir de 2014 se prescindió de la filosofía como componente específico, insertando a cambio las competencias filosóficas en la parte del examen destinada a evaluar la capacidad de lectura crítica de los bachilleres colombianos.

Que la educación en el país y en el continente necesita de una profunda transformación nadie lo pone en duda, pero el verdadero interrogante a debatir versa sobre el sentido de los cambios y sobre todo del modelo político y económico al cual debe servir la nueva educación.

Para no darle más vueltas al argumento, pienso que prescindir de la historia y dejar la filosofía como mero auxiliar de la comprensión lectora, sirve a un proyecto modernizador hegemónico de espaldas a la memoria de las víctimas dejadas a su paso por el huracán del progreso globalizador, como ya Benjamin supo anticipar. Si antes se culpaba a la historia patria de auspiciar un imaginario histórico elitista y 
como hemos visto la historia filosófica y la filosofía de la historia derivadas de la historia de las ideas se cuestionaban por su teleologismo mesiánico, ahora simplemente se eliminan las críticas por simple sustracción de materia.

Reconociendo y asumiendo la fuerza de la deconstrucción reseñada en el apartado anterior, más aún, sosteniendo que una genuina reconstrucción de este modelo no puede menos que incorporar las transformaciones metodológicas derivadas del giro pragmático y de la revisión genealógica, una vez más a contracorriente de los antifundacionismos al uso, deseamos sostener la vigencia de la latinoamericana "historia de las ideas", ciertamente no como paradigma investigativo sobre nuestro pasado filosófico e ideológico, pero sí como matriz del programa de investigación dirigido a elaborar una historia de la filosofía que al constituirse en filosofía de la historia latinoamericana, le dé contenido histórico a la búsqueda de una filosofía peculiarmente latinoamericana.

Tal vez fue John Searle quien señaló alguna vez que “el lenguaje está siempre en orden”, por lo que nos tememos que los cuestionamientos viscerales a la historia de las ideas espetados por Skinner, Pocock, Castro, Palti, y si nos apuran incluso Foucault, en realidad controvierten sus propios supuestos metodológicos, en tanto inconsecuentemente buscan enmendarle la plana a los usos efectivos del lenguaje historiográfico efectuados por los historiadores de ideas que revisan, oponiendo paradójicamente un "antinormativista normativismo" al "normativismo normativista" que ellos detectan en las historias ideológicas tradicionales.

Concentrándonos en la latinoamericana "historia de las ideas", una sana hermenéutica que asuma a plenitud la praxis del discurso histórico, no corregirá a Leopoldo Zea por transfigurar la teleología hegeliana de la libertad en una teleología latinoamericana de la liberación, ya que precisamente ese "metarrelato historiográfico", obedeció en el pensador mexicano a unos usos con intenciones políticas pero también filosóficas que configuran su propio espacio de sentido, como sin duda sucede también con las lecturas pragmáticas y genealógicas que optan por interpretaciones meramente "contingentes" y "efectuales" del pasado.

Si se quiere, el debate se planteará en términos ontológicos referidos a la "permanencia del ser", o epistemológicos concernientes a la "certeza del saber", o incluso éticos y políticos atinentes a la "seguridad de 
la vida buena", pero no tanto sobre los enfoques metodológicos, que al fin de cuentas son un momento derivado de la reflexión.

En el contexto que nos ocupa, la crítica a la misma idea de "América Latina" nos permite ilustrar la réplica que estamos formulando, pues ciertamente que esta denominación posea un origen histórico relativamente reciente, que en el pasado decimonónico surgió de intereses de poder en la configuración del poder neocolonial europeo en la incorporación de esta parte del planeta al orden del capitalismo planetario, y que en la actualidad sirve de retórica geopolítica de unidad que desconoce la diversidad cultural y política que alberga en su seno y así sigue siendo funcional a la globalización trasnacional, no quita que los filósofos latinoamericanos desde Martí hasta Rodó, desde Zea hasta Cerutti, hayan concentrado allí su voluntad de resistencia y sus esperanzas de utopía, en una praxis discursiva alternativa que lejos de asimilarse con los usos conservadores y burgueses, les sirve más bien de cabal alternativa.

Claro está, tampoco podemos pecar de inocencia, e ignorar que invocar hoy el sentido integrador y libertario de "Latinoamérica", implica escarbar en las globalizadas relaciones de poder que la constituyen como espacio político pero también cultural, y reconocer la pluralidad de "mundos de vida" que la conforman, contra esencialismos terrígenas, católicos, liberales, marxistas o incluso posmodernos. Ni Pacha Mama originaria, ni comunidad de base ampliada, ni escala de la civilización demoliberal, ni anhelada sede de la revolución mundial, pero tampoco fragmentados restos del espejo roto, América Latina será o no será lo que sus actores efectivamente hagamos de ella, incluidos en esa permanente construcción, deconstrucción y reconstrucción de su sentido lo que los historiadores edifiquen de ella por medio de su praxis discursiva, llámese esta o no "historia de las ideas".

Si como aduce Pocock en registro austiniano, "To know a language is to know the things which may be done with it..." (1989, p. 28), conocer el lenguaje de la filosofía latinoamericana implica conocer los lenguajes a través de los cuales se ha construido discursiva e históricamente tal cosa como "América Latina", comenzando por los lenguajes de la latinoamericana "historia de las ideas". 


\section{Referencias}

Abellán, J. L. (1979). Historia crítica del pensamiento español. Tomo I Metodología e introducción histórica. Madrid, España: Espasa-Calpe.

Archila, M. Historia social e historia cultural. Encuentros y desencuentros. En M.S. Hering y A.C. Pérez (Eds.), Historia cultural desde Colombia. Categorías y debates. Bogotá: Universidad Javeriana, Universidad Nacional, Universidad de los Andes, 2012, pp. 319- 334.

Berlin, I. (1988). El fuste torcido de la humanidad. Capítulos de historia de las ideas. [Traducido al <español> de <"The crooked timber of humanity">]. Barcelona: Península.

Castro-Gómez, S. (2011). Crítica de la razón latinoamericana. Bogotá, Colombia: Pontificia Universidad Javeriana.

Cortázar, J. (1968). 62. Modelo para armar. Buenos Aires, Argentina: Editorial y.

Cerutti, G. H. (1983). Filosofía latinoamericana e historia de la filosofía. En Hacia una metodología de la historia de las ideas (filosóficas) en América Latina, (pp. 109- 146). México D.F., México: Unam.

Hegel, G. W. F. (1983). Introducción a la historia de la filosofía [Traducido al <español> de <"Vorlesungen über die Geschichte der Philosophie">]. Madrid: Sarpe.

Hegel, G. W. F. (1985). Lecciones sobre historia de la filosofía. Vol I México D.F., México: Fondo de Cultura Económica.

Hering, M. S. y Pérez, A. C. (Eds.). (2012). Historia cultural desde Colombia. Bogotá, Colombia: Universidad Nacional, Pontificia Universidad Javeriana, Universidad de los Andes.

Koselleck, R. (2012). Historias de conceptos. Estudios sobre semántica y pragmática del lenguaje político y social. Madrid, España: Trotta.

Loaiza, G. (2012). "Entre la historia intelectual y la historia cultural, una ambigüedad fecunda”. En M. S. Hering y A. C. Pérez (Eds.), Historia cultural desde Colombia. (pp.347- 363). Bogotá, Colombia: Universidad Nacional, Pontificia Universidad Javeriana, Universidad de los Andes.

Marquínez G., Rodríguez, E. Niño, F. (1996). Ideas y mentalidades: modos de hacer historia. Bogotá: El Búho. 
Oppenheimer, A. (2010). Basta de historias: la obsesión latinoamericana con el pasado. México D.F., México: Debate.

Ortega y Gasset, J. (1962). Ideas para una historia de la filosofía. En E. Bréhier, Historia de la filosofía. (pp. 13-50). (Ed. original, 1942). Buenos Aires, Argentina: Suramericana.

Palti, E. (2005). La invención de una legitimidad: razón y retórica en el pensamiento mexicano del siglo XIX un estudio sobre las formas del discurso político. México D.F., México: Fondo de Cultura Económica.

Palti, E. (2016). De la historia de "ideas" a la historia de los "lenguajes políticos”. Recuperado de https:/gupea.ub.gu.se/bitstream/2077/3275/1/ anales_7-8_palti.pdf

Roig, A. (1993). Historia de las ideas, teoría del discurso y pensamiento latinoamericano. Bogotá, Colombia: Universidad Santo Tomás.

Rorty, R. (1990). Cuatro géneros. En R. Rorty, B Schneewind y Q. Skinner (Eds.), La filosofía en su historia: ensayos de historiografía de la filosofía Barcelona: Paidós, 1990.

Sasso, J. (1998). La filosofía latinoamericana y las construcciones de su historia. Caracas, Venezuela: Monte Ávila.

Scruton, R. (2013). Breve historia de la filosofía moderna. Barcelona, España: RBA.

Skinner, Q. (2007). Visions of politics. Regarding method. Cambridge, England: Cambridge University Press.

Tovar, L. (2001). Historia de las ideas y pluralismo en América Latina. Cuadernos de Filosofía Latinoamericana, Julio- Diciembre, (82-85), pp. 73- 86.

Zea, L. y Miró-Quesada, J. F. (1975). De la historia de las ideas a la filosofía de la historia latinoamericana. En La historia de las ideas en América Latina. (pp. 5-23), Tunja, Boyacá: Universidad Pedagógica y Tecnológica de Colombia. 